\title{
MALIGNANT DISEASES OF THE UPPER AIR-PASSAGES, WITH NOTES UPON TWO CASES OF EPITHELIOMA. ${ }^{3}$
}

\author{
Br J. Price-Brown, M.D., \\ Laryngologist to Western Hospital, Toronto, Canada.
}

I PRESENT the subjects of this paper with diffidence, for already on three different occasions I have expressed my views and related $m y$ experience in the treatment of malignant diseases of the nose and throat to this Association. I was beginninig to think it was too old and trite a story to be inflicted upon you again. Still, I had nothing else to write about, and when our President, in the exceeding goodness of his heart, intimated to me that an article upon any subject would be welcome, I concluded to try your patience once more.

I was encouraged, too, in choosing this subject, by the strong adrocacy of Voltolini's views, so forcibly presented and supported by Bryson Delavan last year in his paper upon naso-pharyngeal fibroma ; and particularly so when such men as Bosworth and Jincoln, Rupricht and Tomassi, Woods and Doyen, all give expression to the view that these growths should be removed by internal, not by external, operations-electrical methods of one kind or other always having the preference, when at all possible.

My argument is, judging from personal experience only, that the treatment so advocated for fibroma is equally applicable to sarcoma, and to a limited extent to epithelioma as well; and that of all methods electrical treatment is the best. It may be by electrolysis, the cautery snare or the electro-cautery knife, one or two or all these combined; but however arranged, in the hands of a skilled, careful and persistent operator, the success which will attend his efforts by these means will far exceed the beneficial results he can obtain by any other method up to the present time known.

If you can do away with the preliminary external operation in naso-pharyngeal fibroma, you can just as effectually do away with a similar operation in naso-pharyngeal sarcoma. They grow alike, have a like origin in the soft tissues of the vault, and the injury to bony structures is more frequently that of pressure absorption than of malignancr within the bone itself. These remarks do not refer

1 Read at the Annual Meeting of the American Laryngological Association, Atlantic City, May 10, 1912. 
to malignancy within the antrum, which, of course, is an involvement of the bony walls, and only amenable when practical at all to external operative treatment.

For twenty years I have alvocated these views, and in the ten ases that I shall refer to, each one has been treated solely by internal methods. Of course, I do not claim originality in the plan of operation, but I do claim to be the first to have carried out the methor of treatment for such a prolonged period, in so many cases and with such gratifying results.

'Twenty-five years ago Bosworth and Lincoln both strongly' advocated the use of the electro-cantery ecrasenr in both fibroma and sarcoma of the naso-pharynx. Fourteen collated cases of fibroma were given, in which eleven were cured and three recurred.

Of sarcoma of the nose treated in the same way the following are reported-

Rahetsch, 1: Removal with galvano-cautery snare. No sulsequent report.

Lincoln, 1: In which two operations had been previously done, followed each time by recurrence. Lincoln then resorted to the electro-cautery loop, and subsequently the electro-cautery knife, with complete success.

Schmiegelow, 1: Removed by electro-cautery snare. No return in seven months.

Major, 1: Galvano-cautery. No return in four months.

Bosworth, 1: Galvano-cautery knife. No return in a year. Also 1: Removed digitally and by curette. No return in six months.

In naso-pharynx-

Lincoln, 1: Removed by galvano-cautery snare. No subsequent report.

Massei, 1: Galvano-cautery snare. No subsequent report.

Bosworth, 1: Cured by oft-repeated use of the galvano-cautery knife and forceps, piecemeal. No return in seven years.

My Case 1 of nasal sarcoma came to me twenty years ago, when Busworth's elaborate treatise was new in my hand.

I need not dwell upon it now, as I reported it to this Association in my first paper upon the subject, except to say that the growth was very large, was located in the right nasal passage, that the treatment consisted in the alternate use of electrolysis and the galvano-cautery, that it took more than six months to remove it. There has been no return, and the man is still in the enjoyment of excellent health. 
Ten years elapsed. Then Cases 2 and 3 came almost together. During that period the trend toward radical operation had developed. Fortunately, my experience in Case 1 had given me faith, and I tried it again, chiefly the galvano-cautery part. Case' 2 recovered as the result of three months' treatment.

Case 3 required electro-cauterisation upon the site of the original growth to be repeated at intervals for six years before the tendency to return was conquered. But it is now four years since he last received treatment; and both of these men are well to-day.

Five years later Case 4 was placed under my care. The growth was removed in similar fashion. The freedom of the nasal passage was restored, and there was no perceptible recurrence; but he died two months later from septicæmia, induced partially by chronic suppuration of the antrum.

Next came Cases 5, 6 and 7, reported at the meeting of this Association in Boston three years ago. Case 5 was cured in a very few weeks by successive electro-cauterisations. The only deformity left was an internal one-the destruction of a large portion of the septum to which the growth was attached. The external nose is normal, and the man is in the enjoyment of excellent health.

In Case 6 vegetations at the site of origin of the tumour continued to recur; but these were very thoroughly burned away by electro-cautery each time that they appeared. I presume now that the vitality of the neoplasm has been conquered, for there has been no return whatever during the last nine months.

Case 7 was the one in which the common carotid was tied one year after commencing treatment, on account of excessive hæmorrhage. This is two years ago now. Although the tying of the artery saved the man's life at the time, it did not put an end to the re-development of the sarcoma; for it still persisted in showing itself at the junction of the posterior choanæ with the vanlt of the pharynx, calling for renewal of the cauterisations. The last, however, was done three and a half months ago, and at the present time there is no sign of re-development. Both these young men are now the pictures of robust health, as their appearance in the last issue of the Transactions indicated.

All these cases presented the usual classical signs. All but one were operated upon by other surgeons before coming to me. All, without exception, were pronounced cases of sarcoma by competent pathologists after careful microscopical examinations, thus verifying the clinical diagnosis.

I now come to Case 8, sarcoma of the larynx, which I reported to 
this Association last year. To be brief, two weeks after our meeting in Philadelphia, the man was well enongh to return to his regnlar. accupation as lithographer, and to continue it for the ensuing fire months. During all this period, however, I required to repeat the destructive operations once or twice a week. If a longer interval was allowed to elapse, the regetations would increase so rapidly, within and without the left side of the larynx, that respiration would be seriously impaired. Still, during all this time, he enjoyed fairly good health, had a normal appetite and easy deglutition.

On January 2 nd last he hal a deeper cauterisation than usual in the region of the left ventricular band above the vocal cords and also external to the left aryeniglottic fold. On the following day while at work he had a severe chill, compelling him to leave the shop and return home. The temperature, which had all along been about normal, ran up quickly to $104 \cdot 5^{2} \mathrm{~F}$. He became very ill. Impending suffocation tollowed. The breath became foul, and the neck on the affected side became tender, red, brawny, and swollen up level with the jaw. It looked like a severe case of localised erysipelas with rapid extension of the disease. I considered the case at last to be hopeless, and expected a speedy euthanasia.

But a change came. In a couple of days the fever abated. The swellng commenced to go down and the patient spat off successive pieces of putrid tissue. Deglutition and respiration improved; and two weeks later the patient returned to my office in good spirits.

On examination I found that large masses of sarcomatous tissue had sloughed away. The affected surfaces looked clean and healthy, and but little of the tumonr was visible.

The neck was much smaller and the glands had shrunken. I kept the case under observation, and for another two weeks there was no reaccession of growth. It looked as though the erysipelatous inflammation-Bacillus prodigiosns like-had made a finishing case of the disease.

But it was not so. For five weeks there were no burnings. Then the life buds of the degenerate appeared again. Once more the gland commenced to enlarge. And from then until now burnings have been resumed.

Three weeks ago, as a last resort, I concluded to try the effect of radium once more, this time as an adjunct to the cautery treatment. The patient has had during this period $20 \mathrm{mgrm}$. of bromide of radium strapped on his neck over the enlarged 
gland for a period in all of seventy-two hours at the rate of about five hours a day. During the same time he has had one cauterisation of the laryngeal growth per week.

I can only say that the conditions are encouraging, but it is too soon to hazard an opinion on the probable result. Physically the man continues well and hopeful.

The new Cases 9 and 10 are both epitheliomata.

CASE 9.-M. F-, plasterer, aged seventy-two, was referred to me at the Western Hospital on November 16, 1911, complaining of a large growth in the left side of the throat, which produced difficulty in swallowing, and was attended by pains shooting up into the ear.

On examination I found an ulcerated tumour occupying the place of the left faucial tonsil, including both anterior and posterior pillars, and attached to the side of the tongue and part of the posterior wall of the pharynx as far down as the back of the thyroid. 'The growth appeared first about a year ago, but during the last few months it had grown rapidly. As the external glands were only slightly swollen and the patient physically was in a fair condition of health, I considered it a better case for combined internal operation than for a radical external one.

The first operation was on the 19 th, three days after. admission. It was divided into three stages. First, under ether, at my request, Dr. Beatty tied the common carotid, in order to control subsequent hæmorrhage. Second, while patient was still unconscious, chloroform was substituted for ether, and I dissected out as much of the tumour through the mouth as I could. Third, I cauterised the base of the growth with the electro-cautery at a white heat. It was impossible to remove every portion of the growth at this operation. Still, it cleared the way widely for future effort. 'There was much hæmorrhage notwithstanding the ligation of the artery. The patient came out of the anæsthetic well, suffered little pain, and expressed himself as more comfortable than he had been for weeks. Soft food was readily taken and he slept well.

During the next two months there were a number of canterisations with the electro-cautery, all under cocaine, the intervals between the treatments gradually increasing in length. The last was done on January 19, exactly two months after the first operation, the intention being to destror all re-forming sarcomatous granulations.

'Three days after the last cauterisation an event similar to the' one recorded of Case 8 occurred. The external throat condition 
became almost identical, while deglutition and respiration remained almost mimpaired. My impression was that the deep tissues of the neck, which could not be reached by operation, had become involved, and as swallowing and breathing could be carried on, the best thing the patient could do wonld be to return to his home in the country and under the care of his physician await the end.

Six weeks later his doctor wrote me that the neck finally broke and discharged freely, thereby relieving the patient. He was in other respects much the same, although he said that the tumour in the throat was again re-forming. The patient himself wrote me that he was coming down soon to see me, but he did not come and I am informed by his physician that the end is near. It is six months since the first operation.

The pathologist pronounced the disease epithelioma.

CASE 10, the last of the series, is a particularly interesting one.

On January 31, 1912, Mrs. W. J. L_-, aged fifty-two, a lady of culture and means, formerly a distinguished vocalist, who had been a throat patient of mine off and on for twenty years, consulted me about a growth in her right nostril. It had been coming on for a number of weeks. It was much intlamed, occluding the passage and attended by stinging pains, which shot up into the ear and side of the face.

On examination I found the central portion of the inner aspect of the right alar and lateral cartilages covered by a reddish, irritable growth, the thickness of a quarter of an inch and coated with muco-pus. On cleaning the part and applying cocaine and adrenalin the growth became clearly defined. It was circumscribed and flat, leaving a clear margin of mucous membrane above and below and backwards between it and the anterior margin of the nasal bone. The nostrils of the lady were clearly defined and delicately formed, but this wing of the nose was altogether more than three times the thickness of the other in its central portion. The redness extended all over the ala of the nose ontside as well as in, and the external skin was tender.

I decided, as it was growing rapidly, to operate the next lay. Chloroform was administered. I then excised the growth with a scalpel. Bleeding was quite free. $A s$ soon as this abated, the patient still under the anxsthetic, I applied the electro-cantery very freely over the surface, and destroyed every portion of suspicious tissue.

The pathologist made a very careful examination of the growth and pronounced it a case of undoubted epithelioma. 
On coming out of the anæsthetic the patient was fairly comfortable and declared herself completely relieved of the stinging pains. The only application was simple white vaseline.

A few days later the patient came to my office, and as suspicious granulations had formed I cauterised two or three under cocaine. Six days later this was repeated. No further development occurred for thirty-two days when spots were cauterised again. 'T'wo weeks later there was a more visible return of the growth in the form of a small ulcer on the top of an inflamed central area. So I decided to remove it again under chloroform the next day. But when twenty-four hours had passed it had trebled in size. Again it was removed by electro-cautery. In three more days there was another return, with a slight extension to the very margin of the nostril. Again the chloroform and again the cautery to each portion more effectually than ever.

Notwithstanding all these severe burnings no part of the cuticle had been sacrificed, neither had any portion of the normal cartilage been lestroyed. The contour of the nose would still be perfect if the re-growth could ouly be arrested. But I began to realise that whike the growth could be positively destroyed with the electrocautery, it was very doubtful if by its use alone re-development could be prevented.

So I decided to call in the assistance of the radiologist. Dr. Aikins before the granulations had time to form again applied 20 mgrm. of the bromide externally, and a tube into the passage. I need not enter into the particulars of his treatment. But I may say that for the past six weeks the patient has been under our mutual control, and by careful and painstaking management, the radium having been used for several hours on a number of occasions, no suspicious granulations whatever have formed during that period. It looks at last like a cure, but no doubt careful watching will be required for some time ret to insure so favourable a result.

It may be asked why in this last case did I not resort to the nst* of radium at the very first. My answer is that I feared any delay might be disastrons. The delicate tissues of the nostril were so deeply involved that immediate destruction of the malignant growth became imperative, and the action of the cautery would be positively quicker than the action of radium. This I believe firmly, while at the same time it is equally clear, from the history of this case, that the judicious use of radimn has prevented the re-formation of the malignant granulations. 
November, 1912.] Rhinology, and Otology.

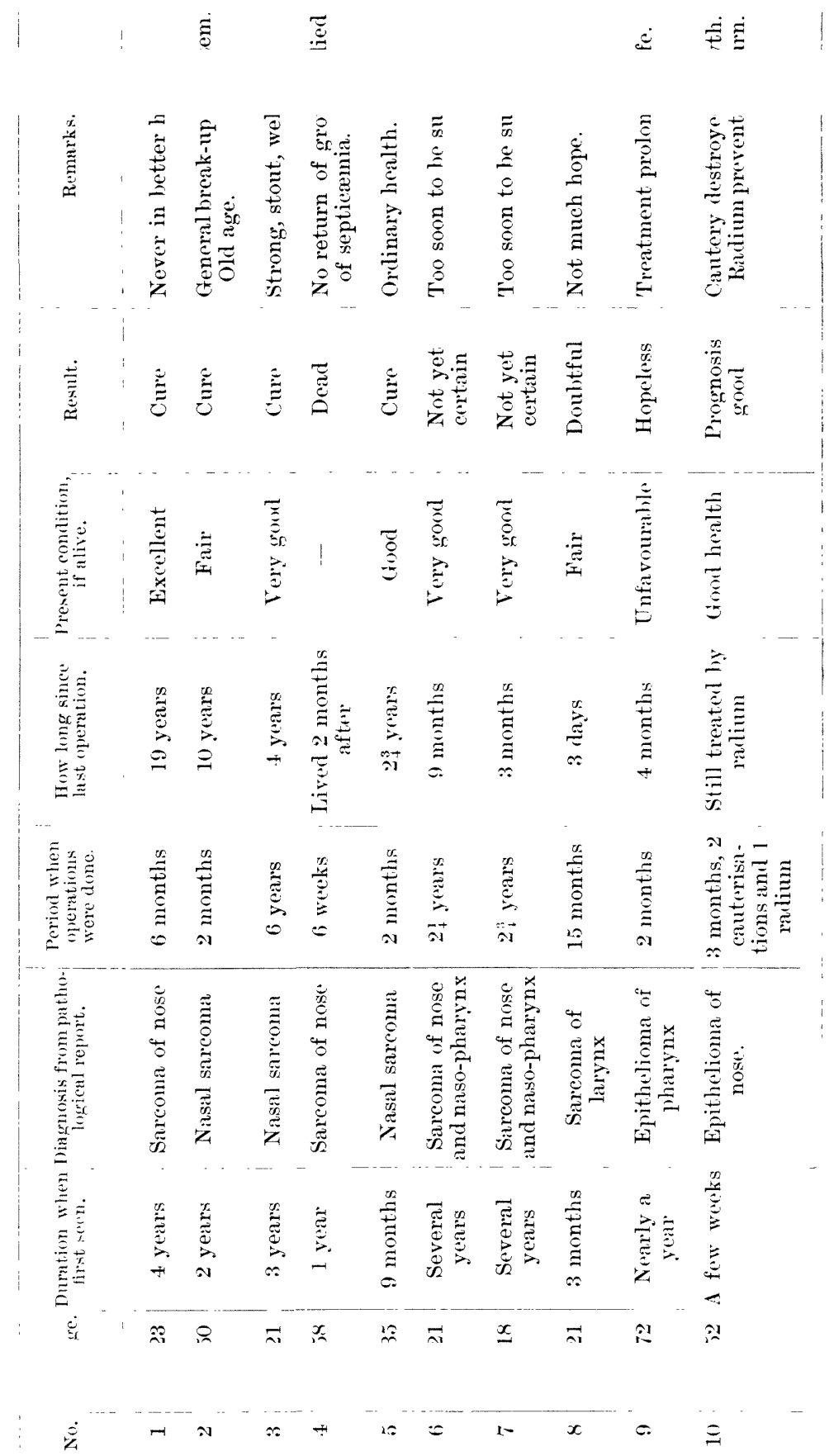

